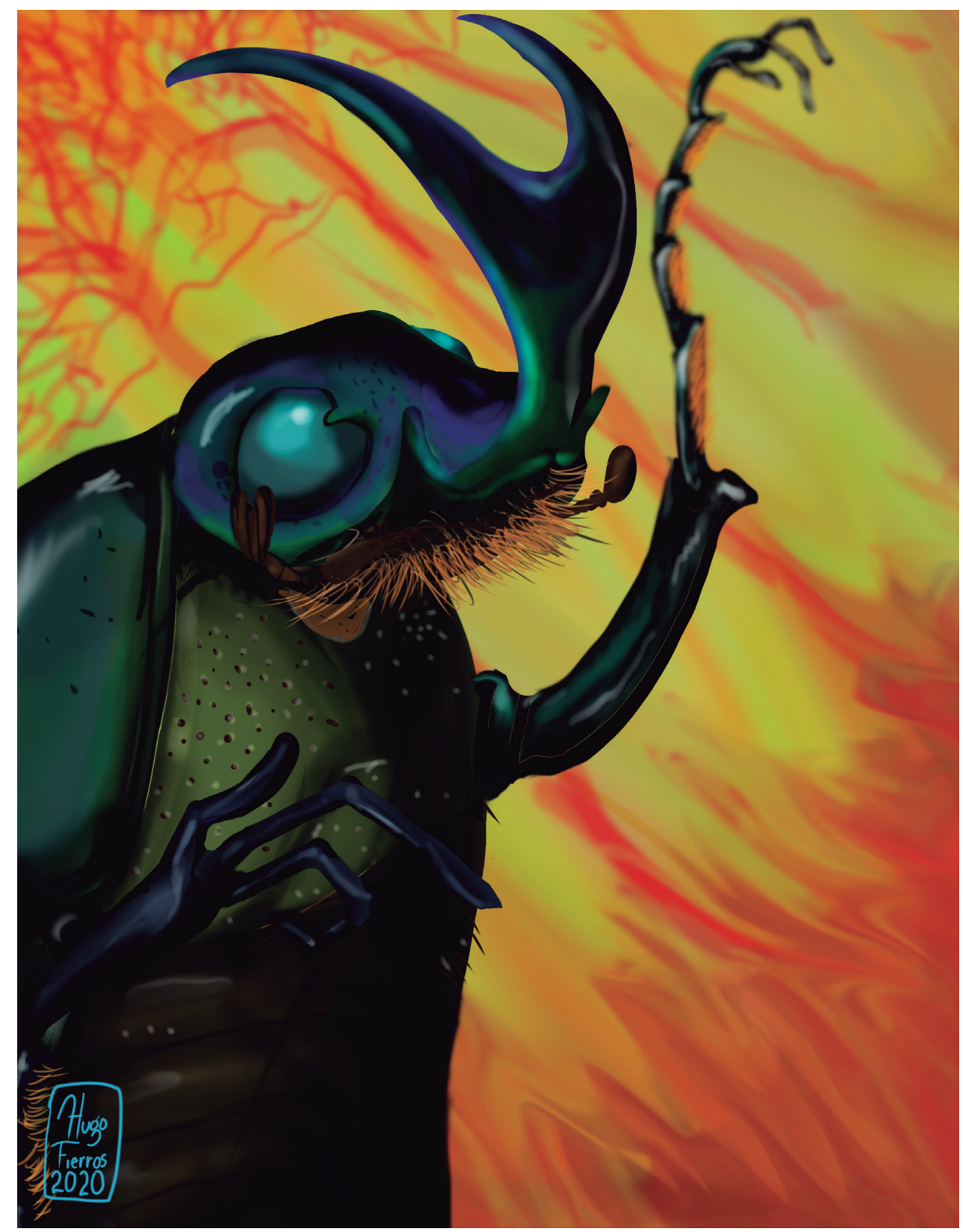

Dugesiana, Año 28, No. 1, (enero-junio, primer semestre de 2021), es una publicación semestral, editada por la Universidad de Guadalajara, a través del Centro de Estudios en Zoología, por el Centro Universitario de Ciencias Biológicas y Agropecuarias. Camino Ramón Padilla Sánchez \# 2100, Nextipac, Zapopan, Jalisco, Tel. 37771150 ext. 33218, http://148.202.248.171/dugesiana/index.php/DUG/index, glenusmx@gmail.com. Editor responsable: José Luis Navarrete-Heredia. Reserva de Derechos al Uso Exclusivo 04-2009-062310115100-203, ISSN: $2007-$ 9133, otorgados por el Instituto Nacional del Derecho de Autor. Responsable de la última actualización de este número: José Luis Navarrete-Heredia, Editor y Ana Laura González-Hernández, Asistente Editorial. Fecha de la última modificación 15 defebrero 2021, con un tiraje de un ejemplar.

Las opiniones expresadas por los autores no necesariamente reflejan la postura del editor de la publicación.

Queda estrictamente prohibida la reproducción total o parcial de los contenidos e imágenes de la publicación sin previa autorización de la Universidad de Guadalajara. 
Artículo

\title{
Nuevo registro de Bothrosternus definitus Wood, 1968 (Coleoptera: Curculionidae Scolytinae) para México y comentarios sobre su biología
}

\section{New record of Bothrosternus definitus Wood, 1968 (Coleoptera: Curculionidae Scolytinae) for Mexico and comments on its biology}

\section{Armando Burgos-Solorio}

Laboratorio de Parasitología Vegetal, Centro de Investigaciones Biológicas², Universidad Autónoma del Estado de Morelos, Av. Universidad 1001, Col. Chamilpa, 62209 Cuernavaca, Morelos, MÉXICO burgos@uaem.mx ORCID: https://orcid.org/0000-0002-8089-6278

\section{RESUMEN}

Se proporciona información sobre el primer registro de la especie de Bothrosternus definitus Wood, 1968, para México, lo que representa el registro más al norteño de la especie; asimismo, algunos aspectos relacionado con la biología de la especie entre la que destaca la forma de la galería y se incorporan imágenes de su hábitus del macho y de la hembra.

Palabras clave: Bothrosternina, distribución, México, Selva Lacandona.

\begin{abstract}
Information is provided on the first record of the Bothrosternus definitus Wood, 1968species for Mexico, which represents the northernmost record of the species; Likewise, some aspects related to the biology of the species, among which the shape of the gallery stands out and images of its habitat of the male and female are incorporated.
\end{abstract}

Key words: Bothrosternina, distribution, Mexico, Lacandona tropical rain forest.

El género Bothrosternus Blandford, 1896 está integrado por 11 especies. La especie tipo es Bothrosternus truncatus Eichhoff, 1868, descrito de Barrancas, Barina Venezuela. Este taxón se distingue del resto de los Bothrosternina por que presenta los márgenes laterales del pronoto afilados y particularmente difiere de Sternobothrus por el área excavada, densamente ornamentada con sedas amarillas, localizadas en la región proepisternal; con una cresta subcarinada tranversa entre las procoxas y las interestrías elitrales carinadas. Las especies de este género tienen hábitos ambrosiales (Wood, 1982). La distribución del género se registra desde Veracruz hasta Argentina (Wood, 1982, Equihua y Burgos, 2002; Alonso-Zarazaga y Lyal, 2009; Atkinson, 2020).

La palabra Bothrosternus proviene del griego bothr-,

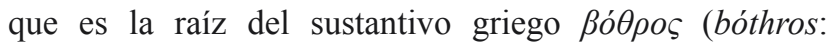
agujero o zanja), luego viene una vocal de conexión (-o-), y por último el sustantivo griego $\sigma \tau \varepsilon \dot{\rho} \rho v o v$ (stérnon: pecho del macho-, de donde el nombre del esternón), En conjunto viene a ser "pecho con un agujero o excavación", a la presencia de propleuras excavadas en el género de Eichhoff (Zarazaga com. pers). (Wood, 1982; Equihua y Burgos, 2018; Atkinson, 2020).

En México sólo se ha registrado a $B$. foveatus (Blackman, 1943) en la región de Cerro Gordo, Veracruz y Matías Romero, Oaxaca (Wood, 1982, Wood y Bright, 1992; Atkinson, 2020).

\section{MATERIALES Y MÉTODOS}

Se realizaron colectas en la parte noreste de Chiapas en las localidades de Palenque y Metzabok, caracterizadas por una selva alta perennifolia (Anónimo, 2018; De La Cruz, $\mathrm{s} / \mathrm{a})$.

Se revisaron y disectaron dos ramas infestadas cuya evidencia de entradas de galería y debris depositadas sobre el suelo y herbáceas en ambos casos las ramas estaban secas en pie; la entrada de la galería se localizaba sobre el tallo o en los nudos de las ramas; La forma de la galería se divide en dos ramas, construida en el parénquima, cuya consistencia es esponjosa, condición idónea para el establecimiento de la galería, la deposición de los huevos y el desarrollo de larvas.

Para la determinación específica, fueron utilizadas las claves de Wood (1982), y ratificadas por el Dr. T. Atkinson de la Colección de Insectos de la Universidad Texas, EUA. El material entomológico se encuentra depositado en la colección entomológica CEUM del Laboratorio de Parasitología Vegetal, del Centro de Investigaciones Biológicas de la Universidad Autónoma del Estado de Morelos, para su consulta. 


\section{RESULTADOS Y DISCUSIÓN \\ Bothrosternus definitus Wood, 1968}

(Figuras 1-15).

Diagnosis: Esta especie se distingue del resto de las especies, porque la hembra consta de una talla de 2.95 a $3.05 \mathrm{~mm}$ de largo, el cuerpo elípticos ligeramente más largos que ancho, de color negro con la hembra presenta frente con convexa de color negro; antena, con el mazo antenal presenta una carina transversal a nivel de la inserción antenal; interestrías elitrales 1-3 carinadas, sobre el disco hasta el declive elitral, excepto en la región del ápice en donde está marcada pero descontinua, marcado por proyecciones ligeramente elevadas evidente en la región del ápice. Márgenes posteriores débilmente levantado, los ángulos redondeados; ornamentación esparcida sobre pronoto y ornamentado con una línea débilmente elevada.

Hembra con las mismas características de la macho excepto con el cuerpo ligeramente más ancho (Figuras 1-6, 13). Cabeza con la frente ligeramente más las larga que ancha, frente rugosa sobre la región del vertex, lisa y brillosa en la parte central con una ligera proyección (Figura 3). Frente sin carina transversal con sedas cortas y decumbentes, superficie corrugada y punteadas situadas por debajo de la proyección; borde anterior del epistoma ornamentado con un grupo de sedas amarillas; mandíbulas ligeramente más grandes y desarrolladas (Figura 5); antenas con el escapo con pocas con sedas erectas, doradas, ápices subplumosos excepto en la hembra (Figuras 6, 12); con seis artejos antenales; mazo antenal más ancho en su parte media, y más aguda en su extremo apical, con dos segmentos delimitados por una hilera de seda blancas Figura 4). Pronoto ligeramente más redondeado en los bordes laterales en vista dorsal; concavidad proepisternal subcuadrada con sedas amarillas en su superficie (Figuras 2-3); línea media del disco pronotal poco evidente; escutelo redondo; élitros con las mismas características del macho, excepto con el declive elitral ligeramente más pronunciado, con los bordes posterior y ápices más redondeados y ligeramente levantados (Figura 1). Carina protoráxica intercoxal ligeramente menos desarrollada; borde del $5^{\circ}$ externito recto en vista ventral (Figura 8). Patas de color pardo oscuras a negras, ornamentadas con sedas amarillas; propatas con tres proyecciones las tibias con dos proyecciones bífidas, separadas desde su base, una más corta que la precedente y en forma de gancho; la tercera contigua, ligeramente separada; mesopatas con tres proyecciones cortas de la misma talla; metapatas con dos proyecciones una más larga que la otra y una tercera, ligeramente separada, más pequeña, localizada en la cara externa de la tibia (Figura 15). Los caracteres morfológicos considerados para diagnosis fueron siguiendo el criterio de Wood (1982).

Distribución: Panamá, Barro Colorado a Costa Rica, Finca Gromaco sobre Río Coto Brus y Peralta, (cuadros negros) (Wood, 1982; Atkinson, 2020), Se amplía el rango de distribución de la especie y constituye un nuevo registro para México (Figura 17). Con relación a la localización de los sitios de colecta y la distribución de esta especie se confina en la región de la Sierra norte de Chiapas y al suroeste la planicie costera del golfo de México, hasta la Isla de Barro Colorado, que corresponde a la Cuenca hidrológica del Canal de Panamá. Derivado de ello la B. definitus, muestra un claro patrón neotropical, asociado a regiones tropicales en donde predomina la selva alta perennifolia. Por otra parte, el clima que se distingue toda esta región está influenciado por grupo "A" acorde a la clasificación de altitudes que no rebasan los $600 \mathrm{msnm}$ con una afinidad climática que va del Aw es decir tropical con invierno seco (lluvias en verano) propios de la región lacandona; y el Af Cálido y lluvioso todo el año, sin estaciones, con clima de la selva lluviosa, clima tipo de Costa Rica y Barro Colorado, Panamá (Anónimo, 2018; Anónimo, 2018a; Anónimo, 2018b; De la Cruz S/A). (Figuras 1-15).

Biología: La forma de la galería es birrameal, con un orificio de entrada principal y dividido en dos ramas centrales, construidas por la hembra. La galería carece de cámara nupcial y no se presentan salidas de emergencia por parte de los preadultos y adultos (Figura 16). En muestras seccionadas se observaron cámaras distribuidas a lo largo de las ramas la longitud de las galerías va de los 8 a $10 \mathrm{~cm}$ de longitud con un diámetro de $1 \mathrm{~mm}$. La forma de la galería es recta o sinuosa, localizada en el parénquima de consistencia suave y esponjosa, lo que le permite a este escarabajo construir la galería con relativa facilidad. En dos muestras analizadas, las galerías localizadas en el parénquima de la planta, estas se encontraban en ramas de un diámetro que va entre los 7 a los $12 \mathrm{~mm}$. En una de las muestras, al disectar las ramas, se encontraron ocho organismos por muestra, de estas seis hembras y dos machos (Figura 16).

Material examinado: México: Chiapas, Palenque, “Panchán”, 17²9'30.01”N 92¹'29.32”O 2018-3-26, 51 m, A. Burgos \& V. Beltrán, AB-2539 (13 우 4 đ̊̄); "Metzabok", Ho chack ak tum, "El Mirador",; Ocosingo, $17^{\circ}$ 7'24.10”N 91³8'11.39”O 2018-07-28, 581 m, Col. A.

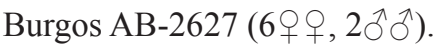

Observaciones. En este trabajo se registra por primera vez para México a Bothrosternus definitus Wood, 1968 colectados en Chiapas.

\section{AGRADECIMIENTOS}

El autor agradece la colaboración del Dr. Miguel Ángel Alonzo Zarazaga, del departamento de Biodiversidad del Museo Nacional de Ciencias Naturales, Madrid España, por para interpretar la etimología del género en cuestión; al Cuerpo Académico de Entomología y Fitopatología AUEM-CA 073, de la DES de Ciencias Naturales, esta actividad deriva del proyecto EXB-48 aprobado por la SEPPROMEP número de convenio 103.5/03/2531, así como el proyecto "Establecimiento de una Colección de Referencia (CEUM)", del Centro de Investigaciones Biológicas, UAEM, PII-69 proyecto, así como el apoyo otorgado por 
la PRODEP-SEP en la estancia académica en la ANPFFMetzabok, Chiapas. Agradezco a las autoridades, en particular al Sergio Montes Quintero, M. en C. Santiago Álvarez-Icaza Landois Icaza, C.P. Guzmán López López y Ing. José Félix Domínguez Hernández de la CONANPComplejo Selva Lacandona, Ocosingo, Chiapas, así como la comunidad de Puerto Bello Metzabok, que sin su ayuda no hubiera sido posible la realización de este proyecto de investigación. Finalmente agradezco al Dr. Thomas Harris Atkinson Martín por la ayuda en la determinación de la especie, asimismo al comité revisor por sus comentario y sugerencia al escrito.

\section{LITERATURA CITADA}

Alonso-Zarazaga, M. A. \& C. H. C. Lyal. 2009. A catalogue of family and genus group names in Scolytinae and Platypodinae with nomenclatural remarks (Coleoptera: Curculionidae). Zootaxa 2258 1-134 pp.

Recibido: 2 octubre 2020

Aceptado: 8 febrero 2021
Anónimo, 2018. Climate-Data.org, 2918) https://es.climatedata.org/location/28384/

Atkinson, T. H. 2020. Bark and Ambrosia Beetles. https:// www.barkbeetles.info/index.php 2020/10/19

De la Cruz, G. G. s/año. Campaña de Educación para la Conservación de los Recursos Naturales Areas de Protección de Flora y Fauna Naha y Metzabok, Selva Lacandona, México. Informe final $50 \mathrm{p}$.

Equihua, M. A., y Burgos, S. A. 2002. Scolytidae. [538-557] En: Llorente B, J, E. González S, y N. Papavero (Eds). Biodiversidad, taxonomía y biogeografía de México: Hacia una síntesis de su conocimiento ISBN- 968-369488-8 Vol. III 1-690 p.

Wood, S.L. 1982. The bark and ambrosia beetles of North and Central America (Coleoptera: Scolytidae), a Taxonomic Monograph. Great Basin Naturalis Memories 6: 11356.

Wood, S.L \& Bright, D. E 1992. A catalog of Scolytidae and Platypodidae (Coleoptera), Part 2. Taxonomic Index (Volumes A, B). Great Basin Nat. Mem. 13: 1-1553. 

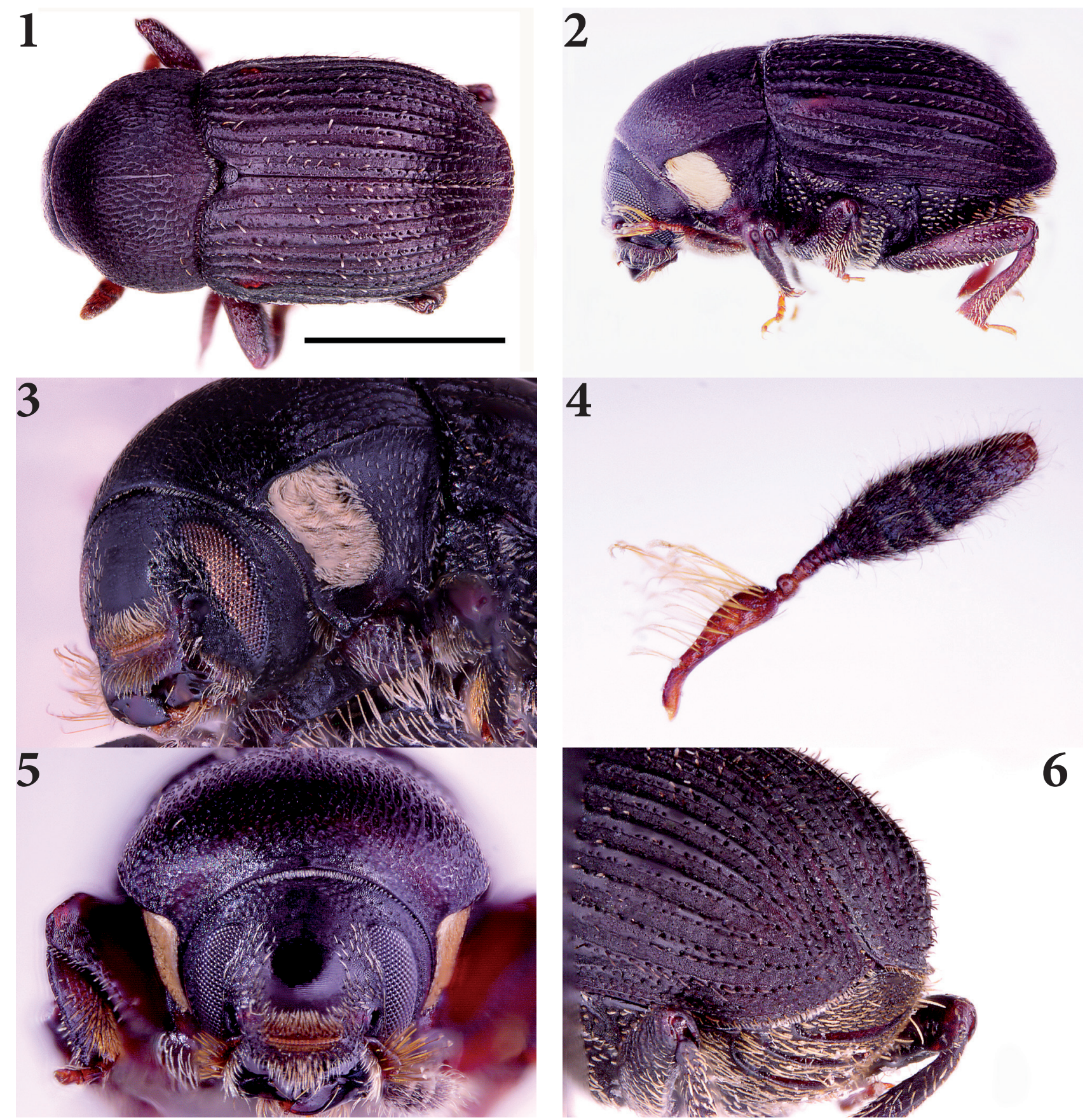

6

Figura 1-6. Hábitus de la hembra $B$. definitus: 1) vista dorsal; 2) vista lateral; 3) Detalle de la cabeza y pronoto; 4) detalle de la antena; 5) Vista frontal de la hembra con la frente lisa y cóncava; 6) declive elitral. La línea representa $1 \mathrm{~mm}$. 

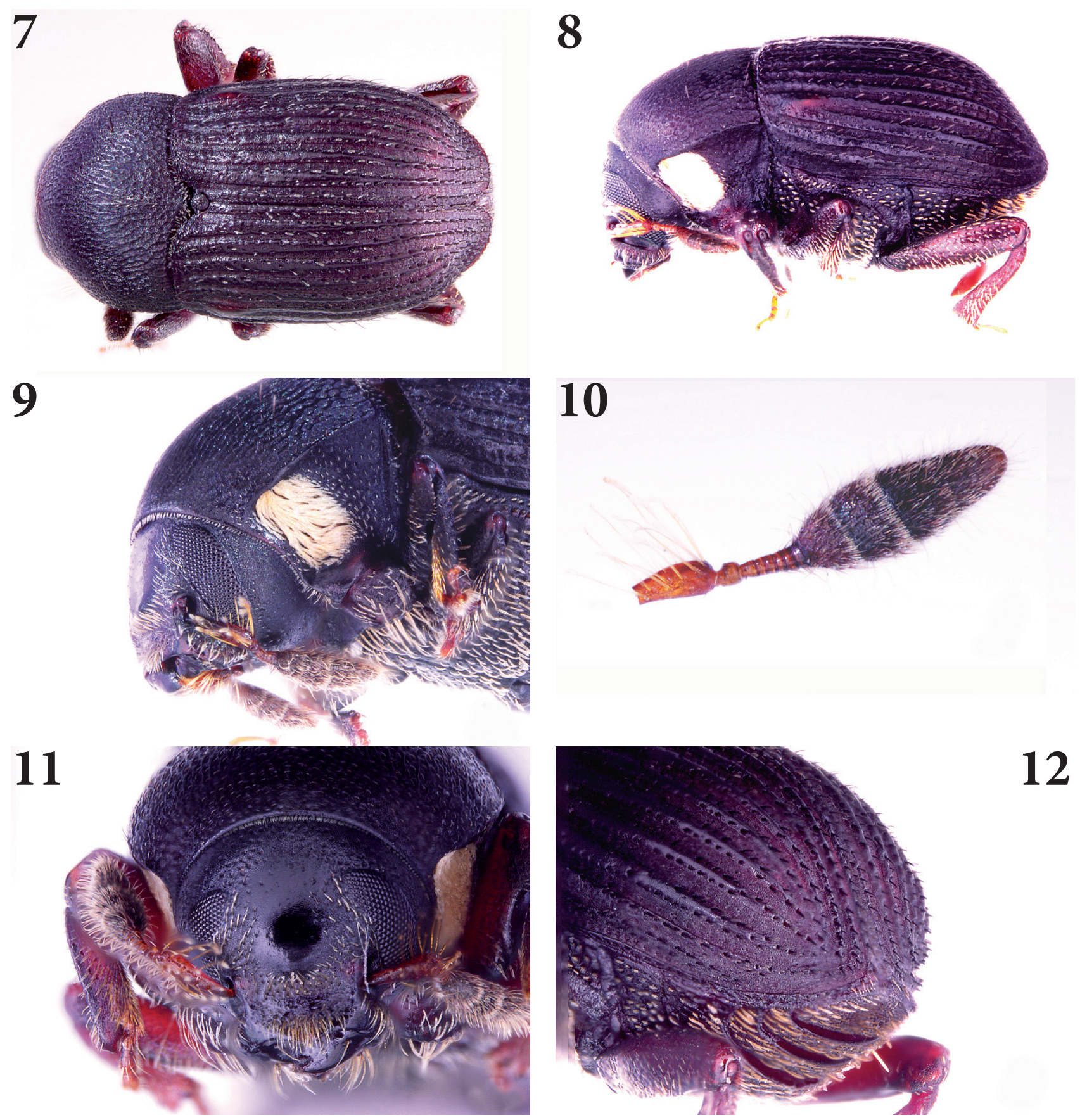

12

Figura 7-12: Hábitus del macho de B. definitus: 7) Hábitus del macho vista dorsal; 8) vista lateral; 9) Detalle de la cabeza y pronoto; 10) detalle de la antena; 11) detalle de la frente mostrando una ligera proyección; 12) declive elitral. 

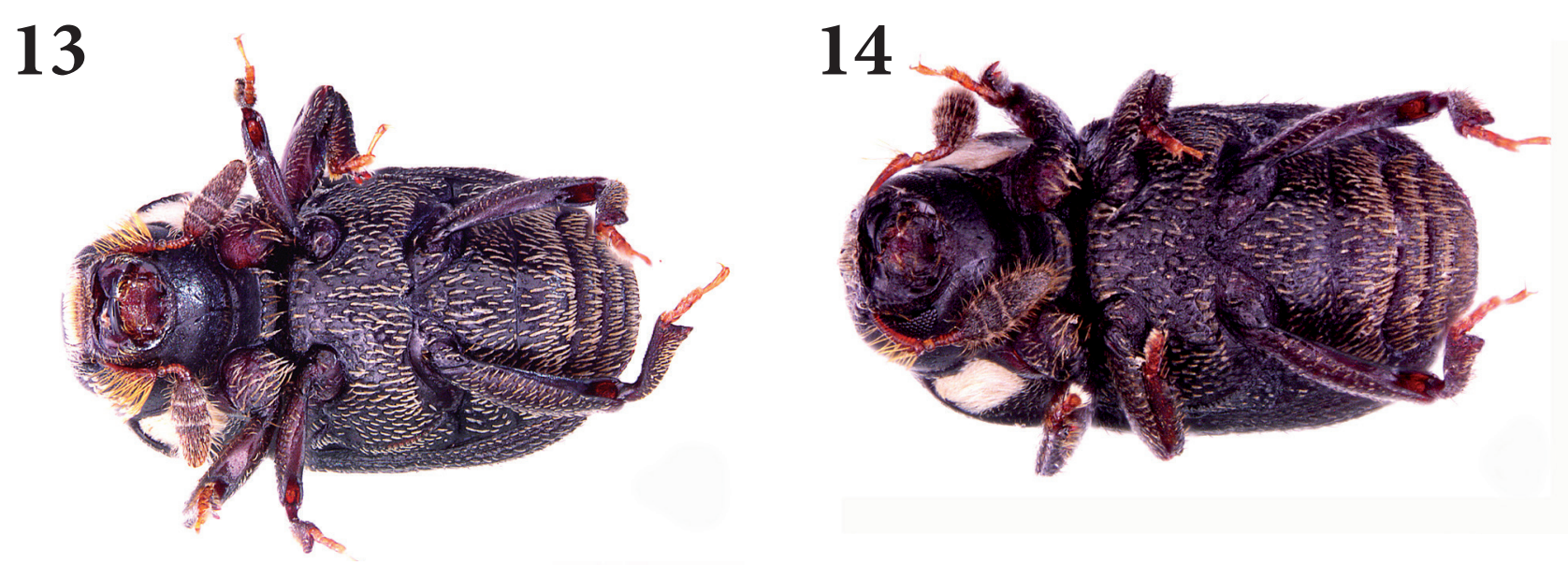

\section{5}
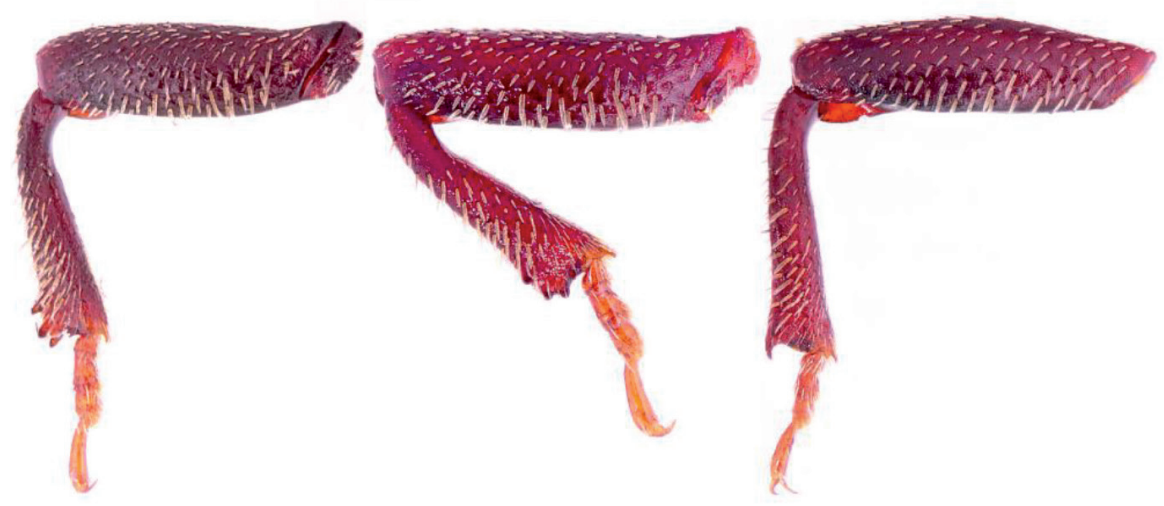

Figuras 13-14. Vista dorsal y ventral de B. definitus: 13) hembra, 14) macho. Figura 15. Pro, meso y metapatas del macho.

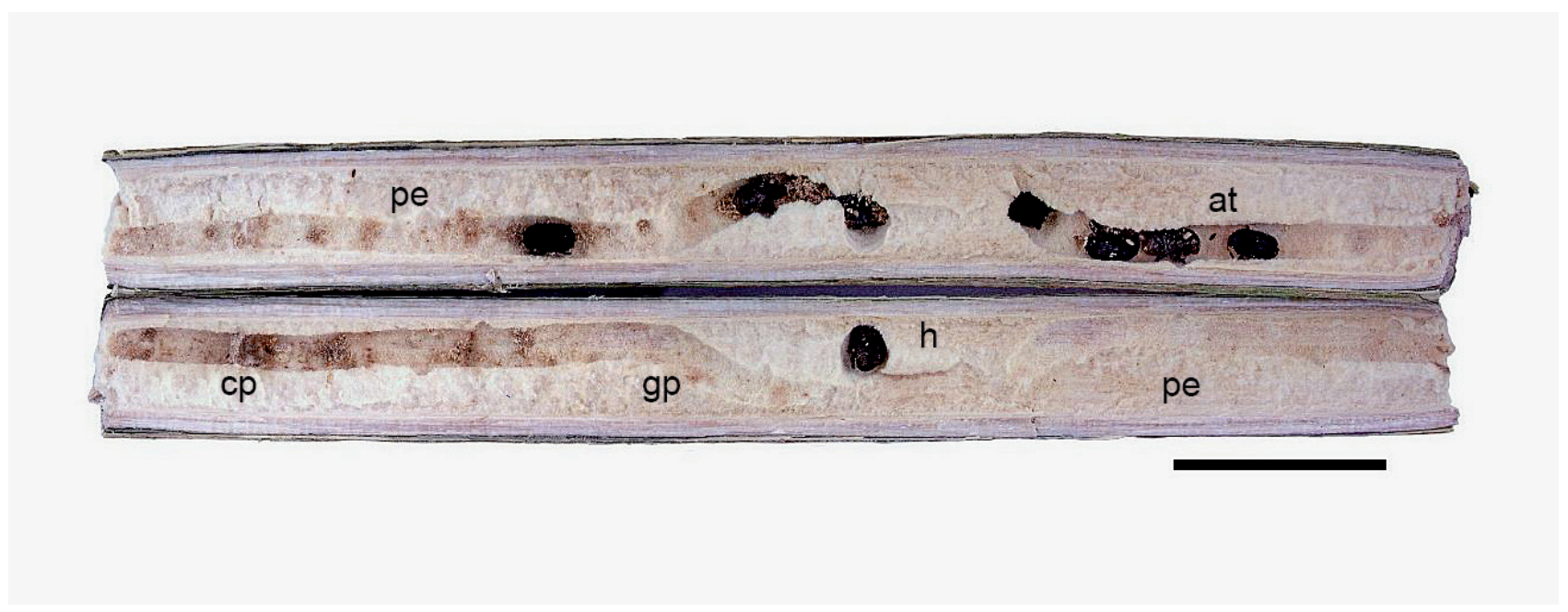

Figura 16. Corte transversal del tallo de la planta hospedera de $B$. definitus $(\mathrm{at}=$ adulto tenerales) $\mathrm{y}$ hembra $(\mathrm{h}=\mathrm{hembra}$ adulta). Nótese la forma de la galería birrameal, sinuosa, distribuida a lo largo del tallo construida por la hembra (gp= galería parental). Se denotan las celdas pupales de los adultos tenerales ( $\mathrm{at}=$ adulto teneral); parénquima esponjoso característico de una herbácea (pe= parénquima esponjoso); La línea representa $1 \mathrm{~cm}$. 


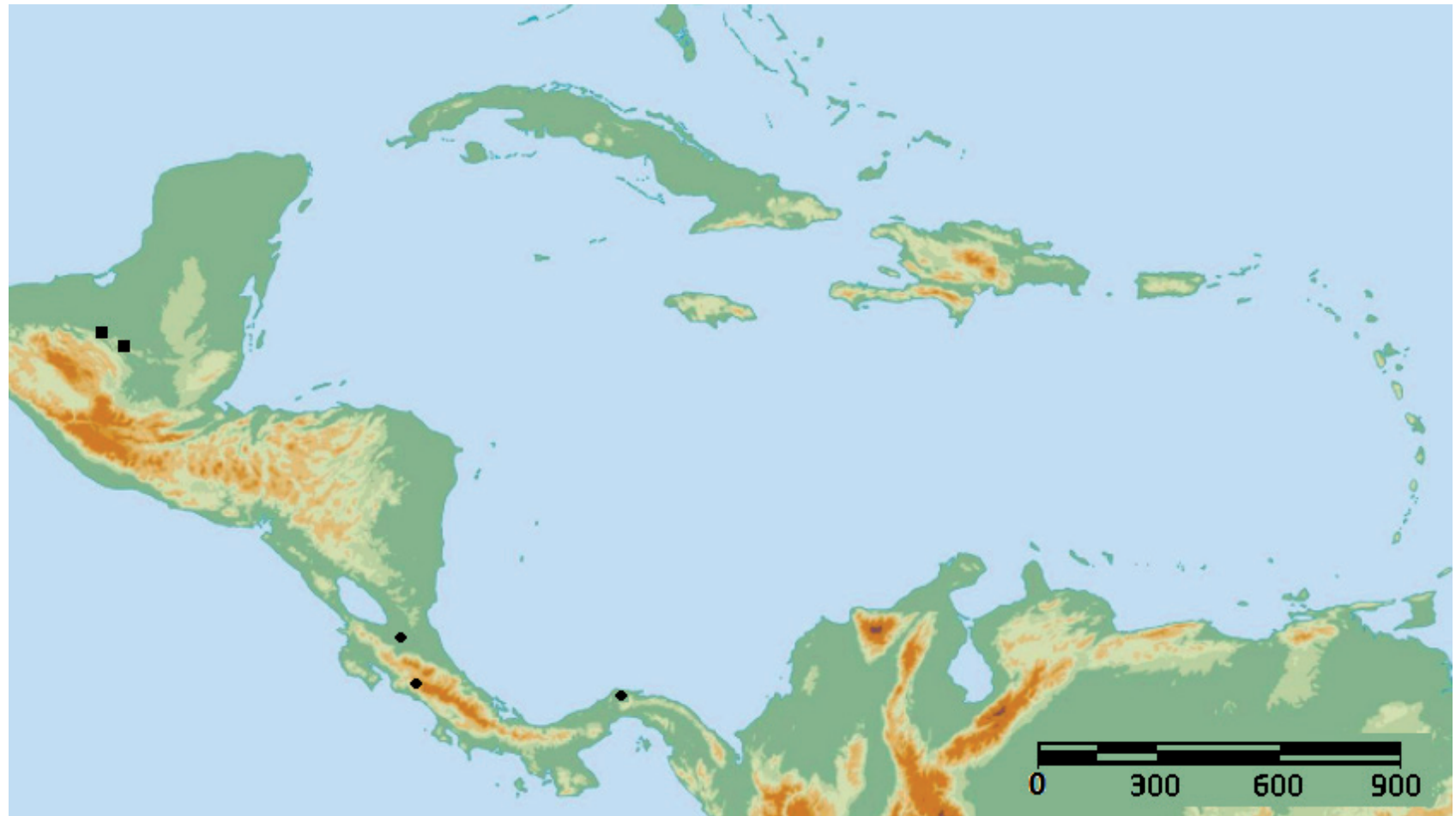

Figura 17. Distribución de Bothrosternus definitus, los círculos son los registros tomado de Atkinson (2020) y los cuadros los nuevos registros para el país. (Tomado de https://www.pinterest.es/pin/299489443947267597/). La barra representa $900 \mathrm{~km}$. 